\title{
Rehun rasvahappojen biohydrogenaatio pötsinesteessä in vitro
}

\author{
Anne Tuomisto \\ Kotieläintieteen laitos, PL 28,00014 Helsingin yliopisto, anne.tuomisto@ helsinki.fi
}

\section{Tiivistelmä}

Biohydrogenaatiota tutkitaan, koska pötsissä tapahtuva rehun rasvahappojen biohydrogenaatio vaikuttaa maidon rasvapitoisuuteen ja rasvahappokoostumukseen. Biohydrogenaation seurauksena märehtijän maito ja liha sisältävät runsaasti tyydyttyneitä rasvahappoja sekä jonkin verran transrasvahappoja.

Pötsissä tapahtuvaa rehun rasvahappojen biohydrogenaatiota on kuitenkin mahdollista säädellä ruokinnallisin keinoin niin, että maitoon erittyy konjugoidun linolihapon (CLA) isomeerejä, joiden on todettu ehkäisevän mm. syöpää, sydän- ja verisuonitauteja sekä rasvan kertymistä kudoksiin. Biohydrogenaatiota säätelemällä on mahdollista vaikuttaa myös maidon rasvapitoisuuteen, pötsissä muodostuvien ja maitoon erittyvien trans-rasvahappojen määrään sekä metaanin tuotantoon pötsissä.

Biohydrogenaatiossa pötsin mikrobit pelkistävät rehun tyydyttymättömät rasvahapot entsymaattisesti välituotteiden kautta tyydyttyneiksi rasvahapoiksi. Välituotteet sisältävät rasvahappoja, joissa on trans-kaksoissidoksia. Myös CLA:t ovat biohydrogenaation välituotteita. Lopputuotteena on yleensä tyydyttynyt rasvahappo. Kaikkia biohydrogenaation välituotteita ja niiden muodostumismekanismeja ei kuitenkaan vielä täysin tunneta. Tämän tutkimuksen tavoitteena oli kehittää panostoiminen in vitro -menetelmä, jolla pystytään tutkimaan pötsin rasvahappojen biohydrogenaatiota välivaiheineen. Lisäksi tavoitteena on tutkia linolihapon biohydrogenaatiota neljällä eri annostasolla ( $1 \mathrm{mg}, 2,5 \mathrm{mg}, 5 \mathrm{mg}$ ja $10 \mathrm{mg}$ linolihappoa).

Työn tuloksena saatiin rasvahappojen biohydrogenaation kuvaamiseen, välituotteiden tunnistamiseen ja niiden muodostumismekanismien tutkimiseen soveltuva in vitro panosviljelmämenetelmä. Menetelmällä aikaansaadussa optimaalisessa linolihapon biohydrogenaatioprofiilissa linolihappo pelkistyy nopeasti. Välituotteena kertyy CLA:ta, eikonjugoituja C18:2-rasvahappoja ja C18:1-rasvahappoja, jotka pelkistyvät edelleen steariinihapoksi. Annostason nostaminen hidastaa linolihapon biohydrogenaatiota ja estää lopputuotteena olevan steariinihapon muodostumista. Panostoimista in vitro -menetelmää käytettäessä on etsittävä rasvahapon sopiva annostaso.

Menetelmää on mahdollista käyttää myös tutkimuksissa, joissa biohydrogenaatiota halutaan säädellä esimerkiksi estämällä biohydrogenaatiota etenemästä loppuun, jolloin maitoon erittyy CLA:ta tai muuttamalla biohydrogenaatioreittiä siten, että pötsissä muodostuu biohydrogenaation välituotetta, joka esimerkiksi alentaa maidon rasvapitoisuutta. Tuloksia voidaan hyödyntää kehitettäessä eläinten ruokintamenetelmiä, joiden avulla maidon rasvapitoisuutta ja rasvahappokoostumusta pyritään muuttamaan. ihmisravitsemuksen kannalta suotuisammaksi.

Asiasanat: biohydrogenaatio, rasvahappo, panosviljelmä, pötsineste, in vitro 


\section{Johdanto}

Biohydrogenaatiolla tarkoitetaan entsymaattista aineenvaihduntareittiä, jossa märehtijän pötsin mikrobit muuttavat rehun tyydyttymättömät rasvahapot välivaiheiden kautta tyydyttyneiksi rasvahapoiksi. Esimerkiksi linolihapon biohydrogenaatiossa linolihappo (cis-9, cis-12 C18:2) muutetaan CLA:n (esim. cis-9, trans-11 C18:2) kautta C18:1-monoeeneiksi (mm. vakseenihapoksi, trans-11 C18:1). Nämä pelkistetään edelleen steariinihapoksi (C18:0), joka on tyydyttynyt rasvahappo (Griinari ja Bauman 1999). Kaikkia biohydrogenaation välivaiheita ei vielä täysin tunneta.

Biohydrogenaatiota tutkitaan, koska pötsissä tapahtuva rehun rasvahappojen biohydrogenaatio vaikuttaa maidon ja lihan rasvapitoisuuteen ja rasvahappokoostumukseen. Biohydrogenaation seurauksena märehtijän maito ja liha sisältävät runsaasti tyydyttyneitä rasvahappoja sekä jonkin verran trans-rasvahappoja, joiden on todettu lisäävän ihmisten riskiä sairastua sydän- ja verisuonitauteihin. Maidon luonnollista trans-rasvapitoisuutta pidetään kuitenkin verrattain alhaisena.

Pötsissä tapahtuvaa rehun rasvahappojen biohydrogenaatiota on kuitenkin mahdollista säädellä ruokinnallisin keinoin niin, että maitoon erittyy konjugoidun linolihapon (CLA) isomeereja, joiden on todettu ehkäisevän mm. syöpää, sydän- ja verisuonitauteja sekä rasvan kertymistä kudoksiin (Belury ym. 2002). Biohydrogenaatiota säätelemällä on mahdollista vaikuttaa myös maidon rasvapitoisuuteen, pötsissä muodostuvien ja maitoon erittyvien trans-rasvahappojen määrään sekä metaanin tuotantoon pötsissä.

Rasvahappojen biohydrogenaatiota pyritään säätelemään niin, että pötsiin kertyy CLA:n esiastetta, vakseenihappoa, jonka maitorauhasen $\Delta^{9}$-desaturaasientsyymi muuttaa maitoon erittyväksi CLA:ksi (Griinari ym. 2000). Vakseenihappoa kertyy, kun sen pelkistystä pötsissä estetään esimerkiksi kalaöljyn rasvahapoilla. Kalaöljyn käyttö lehmien ruokinnassa ei kuitenkaan ole kestävä strategia maidon CLA pitoisuuden tehostamiseksi, ja siksi uusia kalaöljyä korvaavia vakseenihapon pelkistyksen estäjiä tarvitaan. Vaihtoehtoinen strategia maidon CLA-pitoisuuden nostamiseksi perustuu CLA:n pötsipelkistyksen estoon eli CLA:n pötsituoton lisäykseen ilman trans-rasvahappojen tuotannon lisäystä.

Biohydrogenaation säätelyllä voidaan vaikuttaa myös maidon rasvapitoisuuteen. Voimakas väkirehuruokinta alentaa maidon rasvapitoisuutta. Prosessin taustalla on muutos pötsin biohydrogenaatiossa. Muutosta kuvaa ns. biohydrogenaation trans-10 siirtymä, mikä tarkoittaa sitä, että rehun rasvojen biohydrogenaation välituotteena muodostuva vakseenihappo (trans-11 C18:1 rasvahappo) korvautuu suurelta osin trans-10 C18:1 rasvahapon muodostumisella. Trans-10 C18:1 rasvahapon muodostumiseen pötsissä liittyy trans-10, cis-12 18:2 (10,12 CLA) rasvahapon muodostuminen. Toistaiseksi 10,12 CLA on ainoa tunnettu rasvan synteesin estäjä (Baumgard ym. 2000). Usein 10,12 CLA muodostuu pötsissä niin pieniä määriä, että se ei yksin riitä selittämään maitorasvan alenemista. Muita maitorasvan synteesiä alentavia biohydrogenaation välituotteita ei ole vielä tunnistettu.

Edellä olevat esimerkit edustavat tutkimusalueita, jotka hyötyvät biohydrogenaation säätelyn parissa tehtävästä tutkimuksesta, jota voidaan tehdä käyttäen in vitro -laboratoriomenetelmiä. In vitro -menetelmän kehittämistä ja käyttöä biohydrogenaation tutkimiseen puoltavat mittakaavan ja eläinten välisen vaihtelun pienentämiseen liittyvät edut. Laboratoriomittakaavassa tapahtuvan tutkimuksen ansiosta on mahdollista tehdä in vivo- ruokintakokeisiin verrattuna moninkertainen määrä potentiaalisesti vaikuttavien aineiden testauksia käyttäen pötsifistelöityjä lehmiä pötsinesteen luovuttajina. In vitro -menetelmän käyttö vähentää eläinkokeiden tarvetta ja laboratoriomittakaavassa tapahtuva tutkimus säästää kustannuksia.

Tämän tutkimuksen tavoitteena on kehittää panostoiminen in vitro -menetelmä, jolla pystytään tutkimaan biohydrogenaatiotapahtuma välivaiheineen. Tutkimuksessa kuvataan linolihapon biohydrogenaation keskeiset prosessit neljällä eri linolihapon annostasolla. 


\section{Aineisto ja menetelmät}

Panosviljelmässä erillisiin seerumipulloihin lisätään pötsinestettä, puskuria, heinää ja tutkittavaa rasvahappoa (Kuva 1.). Linolihapon annostasosarjoja on neljä (1 mg, 2,5 mg, $5 \mathrm{mg}$ ja $10 \mathrm{mg}$ linolihappoa). Pulloihin lasketaan hiilidioksidia ja niitä inkuboidaan $39{ }^{\circ} \mathrm{C}$ :ssa tasoravistelijassa. Kutakin näytettä inkuboidaan eripituinen aika, jolloin näytteistä muodostuu aikasarja. Näytteistä uutetaan rasvahapot ja ne määritetään kaasukromatografilla. Biohydrogenaatioprofiili esitetään graafisesti rasvahapposubstraatin, välituotteiden ja lopputuotteiden pitoisuuksien muutoksina. Tuloksista lasketaan linolihapon suhteellinen pelkistysnopeus alussa (lineaarisen pelkistysvaiheen aikana), välituotteiden trans-10 C18:1 osuus trans-10 ja trans-11 C18:1-rasvahapoista sekä lopputuotteiden suhde.

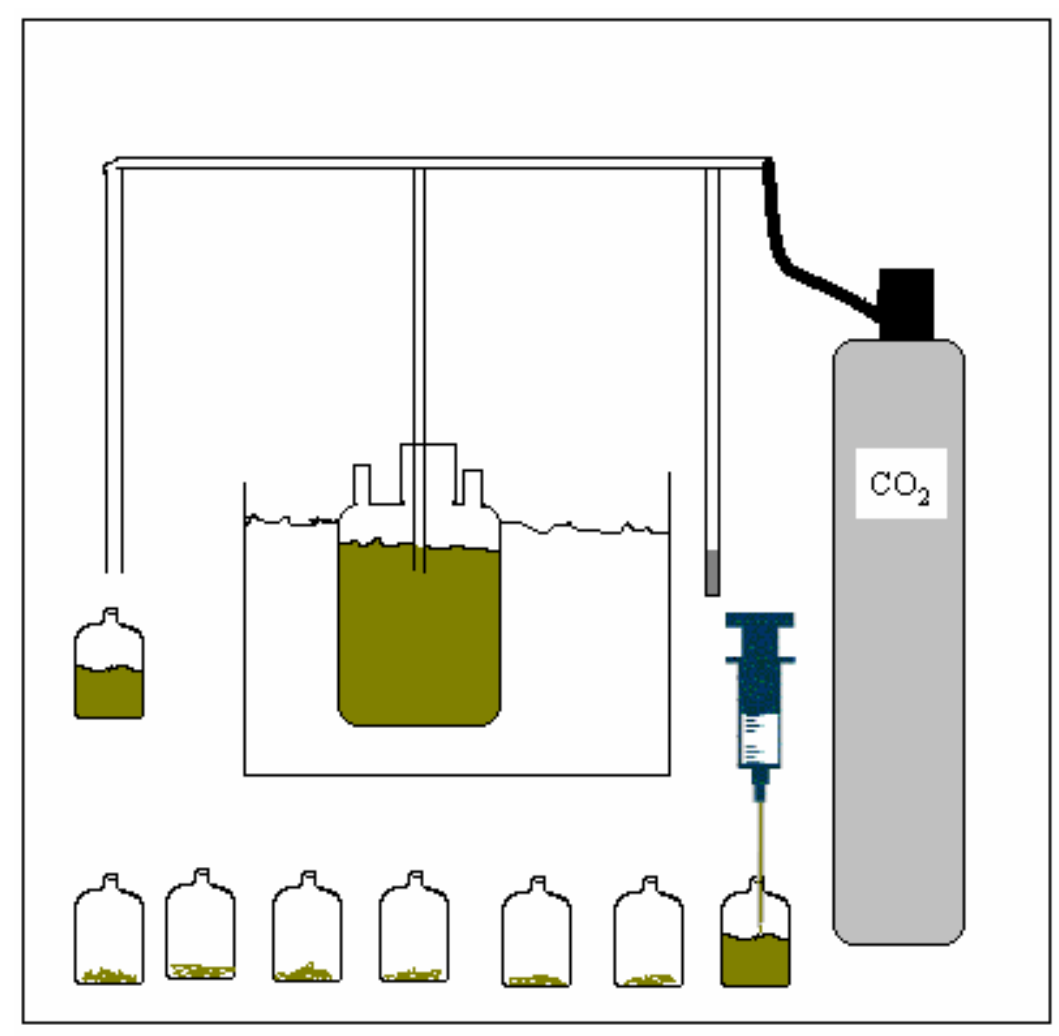

Kuva 1. Pötsinesteen käyttöön perustuva in vitro -panosviljelmämenetelmä rasvahappojen biohydrogenaation tutkimiseen. Isossa astiassa on suodatettua pötsinestettä ja puskuria. Pieniin pulloihin annostellaan heinää, pötsinestettä ja puskuria sekä tutkittavaa rasvahappoa ja hiilidioksidia. Pulloja inkuboidaan $39^{\circ} \mathrm{C}$ :ssa.

\section{Tulokset ja tulosten tarkastelu}

Linolihappo pelkistyi CLA:n ja ei-konjugoitujen trans C18:2 -isomeerien (C18:2 t,t) kautta monoeeneiksi (C18:1), jotka pelkistyivät kolmella alimmalla tässä kokeessa käytetyllä linolihapon annostasolla (1 mg, 2,5 mg ja $5 \mathrm{mg}$ ) edelleen steariinihapoksi (C18:0). Korkeimmalla annostasolla (10 mg) välituotteiden pelkistyminen estyi kokonaan, jolloin lopputuotteena syntyvää steariinihappoa ei kertynyt. (Kuva 2.)

Linolihapon annostason nostaminen pienensi linolihapon suhteellista pelkistysnopeutta $(\mathrm{mg} / \mathrm{h})$ lisättyä linolihappoa kohti kolmen ensimmäisen tunnin aikana tilastollisesti merkitsevästi (2. asteen vaikutus, $\mathrm{P}<0,01)$ (Taulukko 1).

Linolihapon biohydrogenaatiossa syntyvät välituotteet olivat pääasiassa C18:1 rasvahappoja. Lisäksi muodostui ei-konjugoituja C18:2 -rasvahappoja ja hieman CLA:ta (Kuva 2). Jokaisella annostasolla muodostui lähes kaikkia C18:1 -rasvahappojen isomeerejä (Taulukko 2.). Matalimmilla annostasoilla pääasiallisia C18:1-isomeerejä olivat trans-11 C18:1, trans-10 C18:1 ja trans-13/14 C18:1 sekä todennäköisinä in vitro -artefakteina muodostuneet cis-9 C18:1 ja cis-12 C18:1. Korkeimmalla annostasolla muodostui lähinnä trans-11 C18:1- ja trans-10 C18:1 -rasvahappoja sekä cis-12 C18:1 -rasvahappoa. Annostason nostaminen lisäsi lineaarisesti $(\mathrm{P}<0,05)$ trans-10 C18:1 - 
rasvahapon prosenttiosuutta trans-11- ja trans-10 C18:1 -rasvahapoista kolmen tunnin kohdalla (Taulukko 1.).

Biohydrogenaation lopputuotteena muodostui matalimmalla annostasolla lähinnä steariinihappoa. Korkeimmalla annostasolla muodostui steariinihapon sijasta C18:1 -rasvahappoja. Kun linolihapon annostasoa nostettiin, lopputuotteiden C18:0-rasvahappojen määrä C18:1rasvahappoihin nähden väheni lineaarisesti $(\mathrm{P}<0,001)$ (Taulukko 1.).

Aikaisemman käsityksen mukaan biohydrogenaatio on esitetty yksinkertaistetusti kuvan 3 mukaisen kaavion avulla (Harfoot \& Hazlewood 1997). Tämän in vitro-tutkimuksen aineiston perusteella biohydrogenaatiosta on mahdollista esittää kattavampi malli (kuva 4). Pötsinesteessä muodostuu linolihapon biohydrogenaatiossa CLA:n ja vakseenihapon lisäksi muitakin biohydrogenaation välituotteita, kuten ei-konjugoituja C18:2-rasvahappoja ja useita C18:1-isomeerejä. Jouany ym. (2007) ovat havainneet saman in vitro -kokeissaan. Loor ym. (2002) ovat esittäneet eikonjugoitujen C18:2-rasvahappojen olevan biohydrogenaation välituotteita myös in vivo -olosuhteissa. On mahdollista, että biohydrogenaatiossa on ainakin yksi välivaihe, jota ei ole vielä tunnistettu (kuva 4.).

\section{Johtopäätökset}

Rasvahapon annostaso vaikuttaa linolihapon biohydrogenaatioprofiiliin ja muodostuviin välituotteisiin. Linolihaposta muodostuu ensin nopeasti CLA:ta tai vaihtoehtoisesti ei-konjugoituja dieenejä, jotka pelkistyvät useiksi C18:1 -rasvahapon isomeereiksi ja edelleen steariinihapoksi. Annostason nostaminen hidastaa linolihapon biohydrogenaatiota ja estää lopputuotteena olevan steariinihapon muodostumista. Sopiva rasvahapon lisäysannos on etsittävä käytettäessä panostoimista in vitro -menetelmää.

Tämä panosviljelmämalli toimii kvantitatiivisesti ja sitä voidaan käyttää jatkossa esimerkiksi biohydrogenaation käynnistymisvaiheessa muodostuvien välituotteiden ja ei-konjugoitujen transC18:2 ja trans -C18:3 välituotteiden tunnistamiseen. Panosviljelmää voidaan käyttää myös biohydrogenaation säätelijöiden tunnistamiseen. Tuloksia voidaan hyödyntää kehitettäessä eläinten ruokintamenetelmiä, joiden avulla maidon rasvapitoisuutta ja rasvahappokoostumusta pyritään muuttamaan ihmisravitsemuksen kannalta suotuisammaksi.

a)
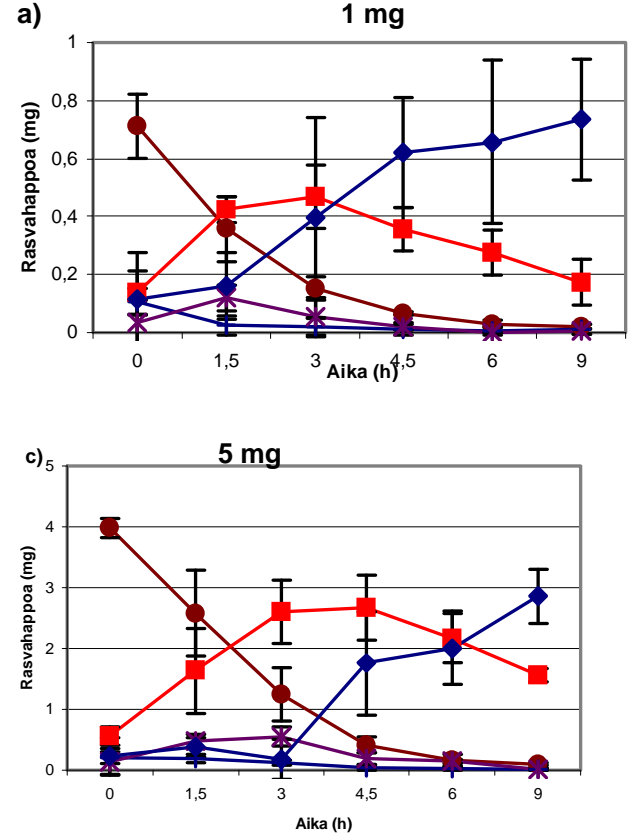

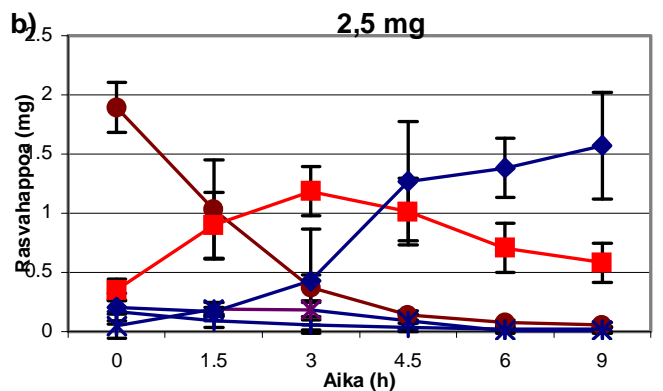

d)

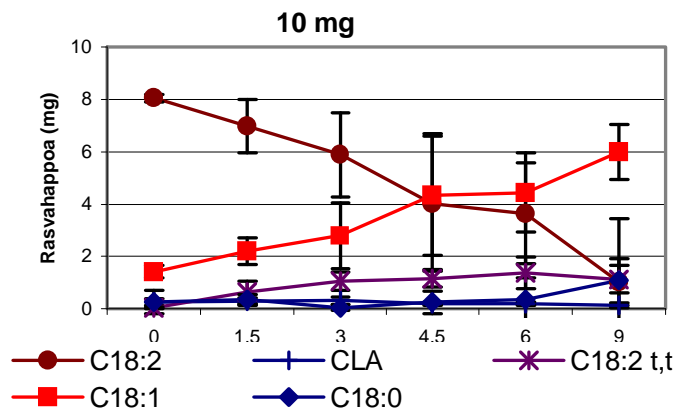

Kuva 2. Linolihapon biohydrogenaatioprofiilien keskiarvot ja keskihajonnat eri annostasoilla. a) $1 \mathrm{mg}$ linolihappoa, b) 2,5 mg linolihappoa, c) $5 \mathrm{mg}$ linolihappoa ja d) $10 \mathrm{mg}$ linolihappoa. Linolihappo (C18:2), konjugoidut linolihapot (CLA), ei-konjugoidut C18:2 -isomeerit (C18:2 t,t), C18:1 monoeenit (C18:1) ja steariinihappo (C18:0). 
Taulukko 1. Linolihapon annostason vaikutus linolihapon suhteelliseen pelkistysnopeuteen, välituotteiden trans-10 C18:1 osuuteen trans-10 ja trans-11 C18:1-rasvahapoista ( $3 \mathrm{~h}$ inkubaatio) ja lopputuotteiden C18:0/C18:1 -suhteeseen (9 h inkubaatio).

\begin{tabular}{l|ccccccccc}
\hline & \multicolumn{1}{|c}{ Linolihapon } & annostasot, $m g$ & & $P$ - arvo & \\
\cline { 2 - 7 } & 1 & 2,5 & 5 & 10 & $S E M$ & $L$ & $Q$ & $S$ \\
\hline $\begin{array}{l}\text { Linolihapon pelkistys- } \\
\text { nopeus, (mg/h)/mg LA }\end{array}$ & 0,19 & 0,20 & 0,18 & 0,07 & 0,016 & $* * *$ & $* *$ & \\
$\begin{array}{l}\text { Välituotteiden } \\
\text { t-10 osuus (t-10+t-11):sta, \% }\end{array}$ & 69,7 & 57,6 & 65,1 & 83,5 & 5,42 & $*$ & $\circ$ & \\
$\begin{array}{l}\text { Lopputuotteiden suhde } \\
\text { (C18:0/C18:1) }\end{array}$ & 3.34 & 2.74 & 1.85 & 0.24 & 0,203 & $* * *$ & & \\
\hline
\end{tabular}

Tilastollinen merkitsevyys: * $\mathrm{P}<0,05, * * \mathrm{P}<0,01, * * * \mathrm{P}<0,001,{ }^{\circ} 0,05<\mathrm{P}<0,10$ ja tyhjä ei merkitsevyyttä.

$\mathrm{L}, \mathrm{Q}$ ja $\mathrm{S}$ viittaavat lineaariseen, 2. ja 3. asteen vaikutuksiin.

Taulukko 2. Linolihapon biohydrogenaatiossa muodostuneet C18:1 -rasvahappojen isomeerit (\% kokonaisC18:1-rasvahapoista) neljällä eri linolihapon annostasolla, C18:1-rasvahappojen huipun kohdalla (1 mg, $2,5 \mathrm{mg}$ ja $5 \mathrm{mg}$ LA $3 \mathrm{~h}$ ja $10 \mathrm{mg}$ LA $9 \mathrm{~h})$.

\begin{tabular}{l|cccccccc}
\hline \multicolumn{7}{c}{ Linolihapon annostaso, $\mathrm{mg}$} \\
\hline & 1 & 2,5 & 5 & 10 & SEM & $\mathrm{L}$ & $\mathrm{Q}$ & $\mathrm{S}$ \\
\hline $\mathrm{t}-6 / 7 / 8$ & 4,3 & 4,6 & 4,3 & 3,7 & 0,717 & & & \\
$\mathrm{t}-9$ & 2,5 & 3,2 & 3,2 & 3,1 & 0,708 & & $* *$ & \\
$\mathrm{t}-10$ & 9,8 & 12,0 & 17,9 & 13,8 & 1,374 & & $*$ & \\
$\mathrm{t}-11$ & 5,9 & 8,5 & 9,3 & 28,4 & 2,725 & $* * *$ & $\circ$ & \\
$\mathrm{t}-12$ & 4,6 & 4,5 & 3,2 & 4,5 & 0,602 & & $* * *$ & \\
$\mathrm{t}-13 / 14$ & 13,9 & 10,5 & 5,7 & 8,3 & 0,959 & $* *$ & $* *$ & \\
$\mathrm{c}-9$ & 7,7 & 9,9 & 13,1 & 9,3 & 1,663 & & $* * *$ \\
$\mathrm{t}-15$ & 5,5 & 3,9 & 1,9 & 2,6 & 0,408 & $* * *$ & $* * *$ & \\
$\mathrm{c}-11$ & 3,3 & 2,0 & 1,6 & 1,1 & 0,654 & $\circ$ & & \\
$\mathrm{c}-12$ & 38,9 & 38,9 & 39,1 & 23,8 & 4,616 & $*$ & & \\
$\mathrm{t}-16$ & 3,6 & 1,9 & 0,8 & 1,5 & 0,733 & & $*$ & \\
\hline
\end{tabular}

Tilastollinen merkitsevyys: * $\mathrm{P}<0,05, * * \mathrm{P}<0,01, * * * \mathrm{P}<0,001,{ }^{\circ} 0,05<\mathrm{P}<0,10$ ja tyhjä ei merkitsevyyttä. $\mathrm{L}, \mathrm{Q}$ ja $\mathrm{S}$ viittaavat lineaariseen, 2. ja 3. asteen vaikutuksiin.

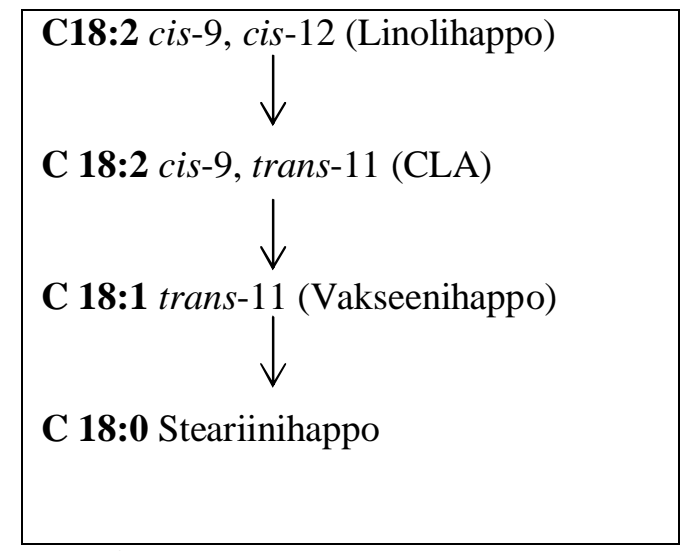

Kuva 3. Yksinkertaistetusti esitetty linolihapon biohydrogenaatioreitti (Harfoot \& Hazlewood 1997). 


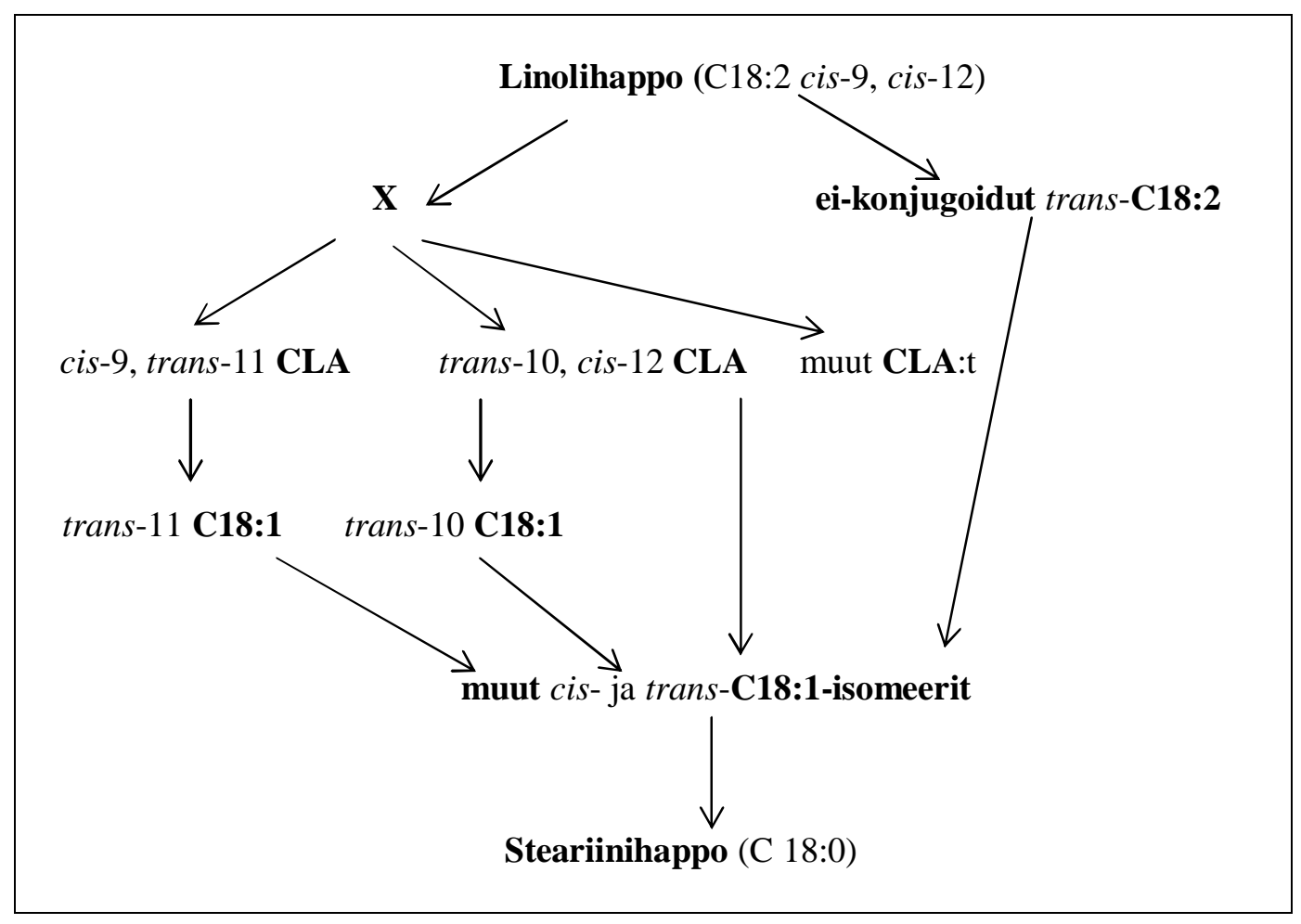

Kuva 4. Mahdollisia muita linolihapon biohydrogenaatioreittejä. $X$ on mahdollinen vielä tunnistamaton biohydrogenaation välituote.

\section{Kirjallisuus}

Baumgard L. H., Corl, B.A., Dwyer D.A., Saebo A. \& Bauman D.E. 2000. Identification of the conjugated linoleic acid idomers that inhibits milk fat synthesis. Am. J. Physiol. 278:R179-R184.

Belury, M.A. 2002. Dietary conjugated linoleic acid in health: physiological effects and mechanisms of action. Annual Reviews of Nutrition 22: 505-531.

Griinari, J. M \& Bauman, D. E. 1999. Biosynthesis of conjugated linoleic acid and its incorporation into meat and milk in ruminants. Yurawecz, M. P., Mossoba, M. M., Kramer, J. K. G., Pariza, M. W. \& Nelson, G. J. (eds.), In Advances in conjugated linoleic acid research, Volume 1, AOCS Press, Campaing, Illinois. p. 180-200. Griinari, J. M, Corl, B. A., Lacy, S. H., Chouinard, P. Y., Nurmela K. V. V. \& Bauman D. E. 2000. Conjugated linoleic acid is synthesized endogenously in lactating dairy cows by $\Delta^{9}$-desaturase. Journal of Nutrition 130: 2285-2291.

Harfoot, C. G., \& Hazlewood, G. P. 1997. Lipid metabolism in the rumen. In: Hobson, P.N., \& Stewart', C.S. (Eds.), The rumen microbial ecosystem, second edition, pp. 382-426. London, UK:Blackie Academic \& Professional.

Jouany J.P. Lassalas, B., Doreau, M. \& Glasser, F. 2007. Dynamic Features of the Rumen Metabolism of Linoleic Acid, Linolenic Acid and Linseed Oil Measured in Vitro. Lipids 42:351-360.

Loor J. J., Bandara A. B. P. A. \& Herbein H. J. 2002. Characterization of 18:1 and 18:2 isomers produced during microbial biohydrogenation of unsaturated fatty acids from canola and soya bean oil in the rumen of lactating cows. Journal of Animal Physiology and Animal Nutrition 86: 422-432. 